taken every hour, and one-twelfth of a grain of tartar emetic every two hours. These remedies were ordered about nine o'clock in the evening.

November 29th. The symptoms had quite disappeared. The medicine made the child vomit once, about twenty-four hours after she began to take it. To-day she was ordered to take the remedies only half as frequently as on admission.

November 30th. She appeared to be free from all danger, and was discharged, cured.

Fiemanks. Of these six cases, it will be observed that the only one which ended fatally was that in which tracheotomy was performed, and the dyspnœa was never so urgent in this case as in that of Payne, who recovered. According to $\mathrm{Mr}$. Wright of Nottingham, who is a surgeon of great experience, tracheotomy in scalds of the glottis almost invariably results in death; and the treatment by leeching, calomel, and antimony, is frequently successful. In the Medical Times and Gazctte, there was lately published a report of fourteen cases of scalds of the glottis in which tracheotomy was adopted. If we add to these fourteen the case which I have published, and another which occurred about two years ago in the Dis. pensary of this town, and which ended fatally, we have sixteen cases of scalds of the glottis in which tracheotomy was resorted to, and, of these, no fewer than thirteen ended fatally, and " in one of the cases which recovered, from certain peculiarities in the history, there is quite room for doubt as to whether the boil. ing water had ever reached the glottis". These facts are in accordance with $\mathrm{Mr}$. Wright's statement, that tracheotomy in scalds of the glottis almost invariably ends in death, and, as far as my observetion has extended, the other part of his state. ment is equally correct, in which he avers that the treatment by calomel, antimony, and leeching is frequently successful. In five of the six cases I publish it was successful, and, I believe, if tracheotomy had not been adopted in the remaining case, it would have been successful in this also.

In scalds of the glottis, I believe it is the best course to commence treatment by calomel and antimony as soon as the accident has happened, although dyspnœa may not be present, and to continue the treatment for forty eight hours, gradually diminishing the doses for the last twenty-four hours. By the early adoption of the treatment the dyspncea may be prevented, or at least mitigated; at all events no harm is likely to ensue from this course. Case v. shows the danger of omitting the remedies, especially the calomel, too soon.

\section{CASE OF TETANUS INFANTUM.}

\section{By I. Harrinson, Esq., F.R.C.S., Fellow of the Obstetrical Society.}

[Real beforc the Reading Pathological Society, October 12th, 1859.]

Mrs. Searle, Orchard Street, aged 24, was delivered of her third child on Friday morning, September 2nd, 1859. It was a male child, fine and apparently healthy in every respect. From Friday till Wednesday all was well. The cord separated on Tuesday, the fifth day. On Wednesday, the child was restless, cried, and kicked. On Thursday, the mother reported that it cried all day; could not open its mouth; could not suck; and frequently stretched, and was stiff.

Next day (Friday), I saw it. Every few minutes it appeared as if struck by an electric shock; every muscle was thrown into distorted action.

I will not attempt to describe. This drawing tells the wrinkled forehead; the elevated brow; the closed eye; the dilated nostril ; the rigid masseter; the fixed jaw; the closed mouth; the corrugated lips; the bubbling saliva; the retracted head; the shortened neck; the starting cervical muscles; the turgid veins; the arched spine; the raised chest; the troubled breathing; the catching diaphragm ; the heaving abdomen; the separated arm; the squared elbow; the bent wrist; the clenched fingers; the incurved thumb; the extended and separated legs; the bent down toes; the livid surface; the whole figure rigid as wood-a pitiful sight.

The paroxysm was renewed by a slight noise, the gentlest ouch. A placid interval of a few minutes succeeded, and then unother fit followed.

On inquiry, I could make little out as to predisposing causes, rr anything favouring the development of such a disease. The nother was healthy; the labour said to be hard, of eighteen lours duration, conducted by a midwife; the child vigorous, at ihe full period; milk abundant; the after care better than in nost of her class; her room small, but unusually clean; no exposure to cold; and there was no surrounding source of noxious agency discoverable.

On examining the child, the umbilicus was seen prominent, at least half an inch long, red, and showing an unhealthy suppurating surface. At this time, there was no alteration in the colour of the skin.

The treatment consisted in having a large poultice constantly on the umbilicus; in warmth, quiet, and getting down as much milk, with a small portion of brandy, as possible. There were intervals, few and far between, in which a fair quantity could be administered. The medicine consisted of magnesia, syrup of poppies, assafœetida, and some aromatic water occasionally given.

I shall not attempt a daily report, as one day's detail differed little from its fellow. The umbilicus continued to discharge till within two days of its death. The secretions were normal throushout. Emaciation rapidly advanced; the skin assumed a brownish hue, and hung in shrivelled folds of leathery texture. Peace and pang pursued their sickening interchange. The child gradually became more feeble; and on the tenth day of the disease, and the fifteenth of its existence, it sank by degrees exhausted.

Post Morten Examination, performed by Mr. George May. Only the abdomen was examined. The umbilicus had gained its usual appearance; nothing morbid was found. The umbilical vein was pervious, and contained a thin bloody fluid. The umbilical arteries were also pervious, but in a less degree than the veins.

Rentarks. Tetanus neonatorum used to be a common disease; now it is very rare. It was an hospital disease, and usually fatal. In the Dublin Lying-in Hosyital, it is said to have killed at one time 17 per cent. ; and that better ventilation reduced this remarkable fatality to 5 per cent.

I need not go into the numerous causes, predisposing and exciting, supposed to have to do with the production of this disease. Confining myself to the class of cases under consideration, I may quote Dr. Copland, who says, "In connexion with the division of the umbilical cord, an impure air, etc., may concur in developing the malady in those constitutionally predisposed to it."

It may here be remarked, that the necessity for a wound of any kind is not absolute for the production of tetanus. Sir Charles Bell says: "In the West Indies, it is produced from exposure to the night air, and most probably from exhalations from the ground. Tetanus is epidemic in Brazil." Most writers believe that the cord has something to do with the origin of tetanus, but they don't know what: all speak indefinitely, except Professor Colles (quoted by Evanson and Maunsell), who shrewdly remarks: "A vitiated state of the atmosphere operates by inducing an unhealthy or unkindly form of inflammation or ulceration at the navel; and that the disease is, in fact, a species of traumatic tetanus, having its immediate cause in the wound occasioned by the separation of the cord." I maintain, with Dr. Colles, that a festering navel is the fons et origo of tetanus infantum. I do not say that tetanus is the only disease that may arise from a festering navel. For example, Mrs. W.'s infant was born before I arrived, and the cord was tied by the nurse; how, I do not know. I did not see it. The child was healthy in every respect. All was well till the morning of the sixth day, when the nurse said it began to look "sorry". On this day the cord came off. I saw it in the evening. It had a grievous look-sunken-clearly from grave mischief. The umbilicus was festering; abdomen distended and hard. It died on the eighth day. Post mortem examination, the umbilicus was red and prominent. There was universal peritonitis. The liver was wholly covered by false membrane.

Speaking from my own limited experience, bruised un healthy wounds are those that favour tetanus. They have been present in two other cases which have occurred to me.

A tradesman, living in Minster Street, aged 31, was thrown out of a pony carriage. He fell on his knees, which were much bruised and wounded, leaving angry sores. Tetanus supervened on the fifteenth day; he died on the nineteenth.

I saw, with MIr. Luce, a boy aged 8 years, whose fingers had been smashed in an agricultural machine. Tetanus came on on the fourteenth day; he died on the nineteenth.

Short notes of the following two cases were taken, because of their recovery. A malignant tumour was removed by $\mathrm{Mr}$. Fergusson, from the tibia of a man, aged 20 . On the 20th day afterwards, tetanus appeared. $\mathrm{He}$ got well. Opium, croton oil, and quinine were used. (Dritish Medical Joursal, October 3rd, 185\%.)

A girl, aged 7 years, was admitted into St. George's Hospital 
under Dr. Jones, with a large ulcer underneath the tongue. Tetanus followed. Cinchona, stimulants, opium and turpentine enemata were employed. She recovered. (BRITISH MEDICAI Journal, August 20th, 1859.)

Such cases show the sort of injuries with which tetanus is connected. Conversely, Sir Charles Bell says, "a kindly suppurating wound is least allied to it." It would seem that the advent of symptoms is as the age, younger the subject, quicker their accession, and vice versa, which is no more than we should à priori expect.

From this sore umbilicus, then, the materies morbi circulates; but whether through the umbilical vein-arteries or surrounding vessels, it is not for me to decide. Dr. West says, "the umbilical vein has presented signs of phlebitis."

Small local sources of formidable maladies may be and are readily overlooked. Take the following case of pyæmia from a boil :- "A man had a small boil just above the right eyebrow, which had been squeezed open. Erythema followed-a soporous state, and death on the fourth day. The seat of the small furuncle was no longer perceptible, yet the vein in the neighbourhood was found filled with pus where it entered the facial vein. From this insignificant place, therefore, the blood had been impregnated with pus." (Dr. Stromeyer, British and Foreign Medico-Chirurgical Review, January 1856.) Take also, "meningitis of the cord, set up by phlebitis of the cervical veins, from chronic disease of the ear." Also, "para plegia associated with gonorrhœa, from phlebitis of the vesica and pelvic veins, extending to the veins of the spine." (Dr. Gull.)

Abscess of the brain and lungs, from a diseased ear, and of the liver, from ulcers of the intestines, are sufficiently well known. Diabetes, from a blow on the head, may also be named.

We have been in the habit of requiring too manifest causes, and too extensive pathological appearances, to satisfy us of their effects and influences-to say nothing of our somewhat saltatory search, which could recognise nothing but bulky alterations-nearly forgetting delicate structure and susceptible function. "We may conclude," says Dr. Gull, " that the spinal cord may have its furctions impaired, and even lost, and that suddenly, as far as the power of motion is concerned, without any distinct amount of anatomical lesion."

"If our knowledge of Pathology," says the Dublin reviewer, " is destined ever to attain precision or perfection, we doubt not it is by directing our inquiries into the causation of disease-to the changes which the vital fluid undergoes. That the blood is vitiated in tetanus, modern authors bear testimony. "A depreciation of the sanguineous fluid originates the malady." ('Travers.) "There is something in the constitution of which the tetanus is the outward and visible sign." (Dr. Snow.) "Under the influence," says the reviewer (British and Foreign), "of certain atmospheric conditions or constitu tions, pernicious atomic groupings may take place within the body, when the normal force tending to resist such changes is inadequate to prevent them."

"A short time only will elapse, says Sir J. K. Shuttleworth, "ere the means of detecting the seeds of disease in the blood, and of ascertaining whether the elements necessary to the due activity of the functions are in the right proportions, will be amongst the common modes of diagnosis in daily use." "How many diseases," he goes on to remark, " in the human body may depend on the imperfection of chemical changes in the assimilatory, or respiratory, or excretory organs, or in the tissues dependent on deficient innervation."

Why the gravamen of such a disordered state should be precipitated on the spinal marrow, may be difficult to deter. mine. I am, fortunately, relieved of this requirement by the recollection of the multiform assault of other poisons ; for example, of the marsh miasm in the production of melanæmia. "'l'here being those cases," says Dr. Wilks, "where the cere. bral symptoms predomirated, those where the kidney is principally affected, those where the digestive organs and liver suffer, and those where the symptoms are merely those of anæmia." In tetanus, most probably, some allotropic variety of pus determines the site. That it should have a specific influence-that it should operate as it does when so precipitated is not more singular than the action of the oxytoxic ergot of rye, which, as Dr, Tyler Smith says, "passes into the blood, and affects the spinal centre, being specially directed to the lower portion of the spinal marrow, and to that part of it in relation with the uterus."

Treatment, under such a pathology, would naturally resolve itself into the preventive, special and general. The preventive would consist in the proper management of the cord. This became separated, in the case under discussion, it will be remembered, on the fifth day, two days before the usual time.

Dr. Boiveau observed, that all those attacked presented marks of inflammation about the umbilicus; considering it, therefore, traumatic tetanus, he recommended the dressings should not be removed from the cord before the fifteenth daya practice attended with success. The period of separation will of course vary; but one thing is certain-its dropping off should not be prematurely facilitated by the pulls it often get at the hands of nurses, to whose tender mercies this duty is conventionally entrusted.

The conversion of a festering into a kindly sore would be conducted on acknowledged surgical principles. It would demand our first and best attention, on the ground causi ablatâ tollitur effectus. Sir C. Bell says, " such a condition of the wound we often desire, as most like to put a stop to its violence."

The general treatment would be that of pyæmia and of its kindred affections, of which tetanus is undoubtedly one. On appropriate stimulants, largely administered and diligently sustained, we may hopefully base our principal reliance. Under such a plan and its associated addenda, I do not despair seeing tetanus one of the most tractable diseases of its class.*

\section{MYALGIA AND MYOSITIS.}

By Thomas Irwan, M.D., Physician to the Liverpool Royal Infirmary.

CASE I. Jane M., aged 20, a milliner's shopwoman, was admitted October 20, with pain and stiffness of both lower extremities. She was of average size, stout, and apparently well nourished, but had lost all appetite for food for the last three months. Her business compelled her to stand in or walk about the shop the whole day. About a week before admission, the legs began to be painful, and when she came into the Hospital they were so bad that she could not walk without great suffering. She was unable to bend either knee, and "stumped" about on her heels, as if on wooden supports. The posterior part of both thighs and legs were of brawny hardness, and tender to the touch. She was ordered to lie in bed, and to take steel mixture. At this time, there was no sign, externally, of inflammation. The first part of my recommendation the patient would not submit to, until the next patient came in and she overheard my remarks to the students on her case; she then took to bed. In seven days after rest in bed, the left leg was quite well, soft, comfortable, painless but on the right leg there was, at the upper part of the calf, a spot which remained hard, brawny, and tender to the touch. In seven days more there was cutaneous redness, and increased tenderness; and in another seven days a large abscess was opened, which had formed between the soleus and gastrocnemius. A large sinus forming, the patient was transferred to a surgical ward, where she ultimately recovered.

Probably the patient would have recovered without suppura tion, had she rested the limb at the first when ordered to do so.

CASE II. Ann B., aged 22, a servant at an hotel, was admitted October 27 , with precisely similar symptoms as Jane M. She was stout, but pale; her occupation consisted chiefly in standing at a dresser washing glass and crockery, and "from the time she left bed until her return to it she never sat down, except for a few minutes at dinner." Twelve months ago, she had been obliged to leave her place from excessive in framammary pain, which had been cured by rest and tonic medicines. She had been able to do her work tolerably well until her strength failed her, in consequence of menorrhagia and total anorexia. The posterior parts of the lower extremities were of brawny hardness, and very tender to the touch; there were muscular pains about the abdomen and lumbar region, but of no great severity.

She was ordered to lie in bed, with cotton-wool around the calves to keep off the roughness of the bed linen; and to take twenty minims of the tincture of sesquichloride of iron three times a day. Improvement was perceptible in three days, and she left the house, quite well, in a fortnight.

* Since reading this paper, I have observed that the view of the toxami origin of tetanus has been advocated by Dr. B. W. Richardson, in a paper on Zymosis, read before the Epidemiological Society (Brit. MED. JournaL, ov. 19, 1859); and by Mr. S. Wells, in a paper read before the Royal Medical and "Chirurgical Society (Jouknal, Dec. 3, 1859). Dr. Richardson, it is stated, "claimed tetanus to be essentially zymotic. His theory of its pro duction in traumatic cases was that the wound, in the process of healing, ment.; I. H. 